\title{
TECHNOLOGICAL ADVANCES IN THE UNIVERSITY OF WASHINGTON ACCELERATOR MASS SPECTROMETRY SYSTEM
}

\author{
G W FARWELL, P M GROOTES, D D LEACH, AND F H SCHMIDT \\ Nuclear Physics Laboratory \\ University of Washington, Seattle, Washington 98195
}

\begin{abstract}
During the past year we have continued to work toward greater stability and flexibility in nearly a11 elements of our accelerator mass spectrometry (AMS) system, which is based upon an FN tandem Van de Graaff accelerator, and have carried out measurements of $1{ }^{14} \mathrm{C} / 1{ }^{2} \mathrm{C}$ and $10 \mathrm{Be} / 9 \mathrm{Be}$ isotopic abundance ratios in natural samples. The principal recent developments and improvements in the accelerator system and in our sample preparation techniques for carbon and beryllium are discussed, and the results of a study of ${ }^{10} \mathrm{Be}$ cross-contamination of beryllium samples in the sputter ion source are presented.
\end{abstract}

\section{INTRODUCTION}

As all scientists engaged in accelerator mass spectrometry (AMS) are aware, the apparently simple task of adapting an accelerator constructed primarily for use in nuclear physics experiments to the measurement of minute isotopic fractions becomes formidable when accuracy in the $1 \%$ range (counting statistics permitting) is desired. During the year following the 1981 Symposium on Accelerator Mass Spectrometry held at the Argonne National Laboratory, where we reported our results up to that time (Farwe11, Schmidt, and Grootes, 1981; Grootes et al, 1981), we have made substantial progress toward the desired $1 \%$ capability.

Particular effort has been given to enhancement and stabilization of the overall ion transmission of the accelerator, to improvements in the cesium sputter ion source, to the measurement of cross-contamination among beryllium samples in the ion souce and the reduction of the 10Be background of our system, to the construction of an automatic low-energy beam control system that enables concurrent measurement of $12 \mathrm{C}^{-}$ and $14 \mathrm{C}^{+4}$ beams from alternating samples, and to the study of other normalization arrangements. We have also given much attention to the preparation of beryllium and carbon ion source samples from natural materials, including the graphitization of carbon into pellets that give high ( $\left.>10 \mu \mathrm{A} 12 \mathrm{C}^{-}\right)$ and very stable ion yields. These developments are discussed in more detail below; the results of recent measurements of 
isotopic abundance ratios are reported in a companion paper (Farwe11 et al, 1983).

\section{ION SOURCE AND LOW-ENERGY BEAM TRANSPORT}

A number of changes were incorporated into the cesium sputter ion source, including a better ion-forming electrode, steering electrodes for the negative ion beams, and improved electrode and sample alignment. These measures made it possible virtually to "dial-set" the source parameters in advance to produce any desired output of ${ }^{12} \mathrm{C}$ ions ranging from $0.5 \mu \mathrm{A}$ to $15 \mu \mathrm{A}$, and resulted in increased ion output and stability for beryllium beams as well.

A substantial improvement in the ion optics of the lowenergy beam system resulted from installation of a more highly stabilized power supply on the $12.5 \mathrm{~cm}$ Einzel lens downstream from the inflection magnet. The mass resolution of the negative ion injection system was thereby increased from $M / \Delta M \simeq 30$ to $M / \Delta M \simeq 90$.

To facilitate rapid shifts of the AMS system from one isotope to another, we installed a two-level nuclear magnetic resonance controller on the inflection magnet; this was particularly useful in the beryllium studies and in the carbon studies in which normalization against ${ }^{13} \mathrm{C}$ is used.

Finally, an automatic low-energy beam control system was installed which enables concurrent measurement of $12 \mathrm{C}^{-}$and ${ }^{14} \mathrm{C}^{+4}$ beams; this provides a means of comparing the ${ }^{14} \mathrm{C} /{ }^{12} \mathrm{C}$ ratios of two alternating samples, a standard and an unknown (Farwell et al, 1983; Schmidt and Fauska, 1982).

\section{ACCELERATOR TRANSMISSION: THE GRIDDED LENS}

During much of the past year our studies were seriously affected by a deterioration in the overall ion transmission of the tandem Van de Graaff accelerator. However, it appears that the primary transmission problem has been solved, and recent operation has been much more satisfactory for the AlIS studies. The transmission problem was associated largely with a gridded lens placed at the entrance to the accelerator tube. When this grid was first installed in May 1980, transmission of the carbon beams was increased nearly threefold. Other benefits were also derived from the grid -- most notably, a marked reduction in the criticality of low-energy tuning parameters. (This lack of criticality is very 
important when operating with a beam for which a current cannot be measured, as for ${ }^{14} \mathrm{C}$ or ${ }^{10} \mathrm{Be}$.)

These benefits were seriously offset, however, by several grid-related phenomena: a lateral displacement of the high-energy beam, a reduced ability for the tandem accelerator to hold full voltage ( $9 \mathrm{MV}$ ), and increased $\mathrm{X}$-radiation. These problems have been largely resolved by the installation of a suppressor magnet for electrons generated at the grid by the negative ion beam, together with three upstream compensating magnets to correct for beam displacement and deflection by the suppressor. With more favorable conditions resulting from these improvements it has been possible to achieve ${ }^{14} \mathrm{C}$ counting rates of ca 1500 per minute for 1950 carbon samples that give ${ }^{12} \mathrm{C}^{-}$(low-energy) beams of ca15 $\mu$.

The tandem accelerator is usually operated with a terminal voltage of $7.00 \mathrm{MV}$; the final ion energies are then $35.0 \mathrm{MeV}\left({ }^{14} \mathrm{C}^{-} \rightarrow{ }^{14} \mathrm{C}^{+4}\right)$ and $23.7 \mathrm{MeV}\left(10_{\mathrm{Be}}{ }^{16} \mathrm{O}^{-} \rightarrow{ }^{10} \mathrm{Be}^{+3}\right)$.

\section{SAMPLE PREPARATION: CARBON}

The production of small pellets (8 to 10mg) of graphite from wood samples or cracked carbon was described earlier (Grootes et al, 1980; Grootes et a1, 1981). We have devised completely new equipment to make the process more reproducible and reliable. Carbonized and pulverized wood is mixed with 20\% heavy hydrocarbon binder ("pitch") in a molybdenum mold. A set of six molds is gradually heated to $1000^{\circ} \mathrm{C}$ in a nitrogen atmosphere while pressure is applied to the carbon mixture to form it into a wafer of appropriate shape for insertion into the sputter ion source. The wafers are subsequently removed from the molds and heated under vacuum to $2500^{\circ} \mathrm{C}$ in a graphite holder inside a heavily heat-shielded graphite furnace. This produces graphitic wafers that are truncated cones, $0.090 \mathrm{~cm}$ high $\times 0.236 \mathrm{~cm}$ base diameter, with a cone angle of $20^{\circ}$. They are of uniform size, weigh ca $4 \mathrm{mg}$, give beams of $12 \mathrm{C}^{-}$ions equal to or greater than high-grade commercial graphite, and reach $80 \%$ to $90 \%$ of peak output within 2 minutes after first being moved into position and subjected to the Cs sputtering ion beam.

This technique produces good graphitized carbon samples directly from wood. A more general sample preparation procedure, however, must be able to use $\mathrm{CO}_{2}$ which can be prepared in a pure form from any carbonaceous material. Conversion of $\mathrm{CO}_{2}$ into carbon is under study at the 
Quaternary Isotope Laboratory. Reduction of $\mathrm{CO}_{2}$ to $\mathrm{CO}$ over hot zinc followed by decomposition of the CO in à DC glow discharge (cracking) produces high quality carbon suitable for graphitization. The process is, however, time-consuming and the effect of gas pressure and discharge current on the cracking process needs further study.

An alternative and much faster route to elemental carbon uses reduction of $\mathrm{CO}_{2}$ with magnesium at $900^{\circ} \mathrm{C}$. Reductions between $80 \%$ and $100 \%$ can be reached without significant isotope fractionation in 5 to 10 minutes. Substantial chemical purification is required to eliminate the $\mathrm{Mg}$ and $\mathrm{MgO}$ and parts of the vicor tube used for the reduction. In addition, the carbon must be powdered and baked at $1000^{\circ} \mathrm{C}$ before it can be used for pellet production. Unfortunately, impurities remain in the mixture and cause serious deterioration of the pellet during the graphitization process.

\section{SAMPLE PREPARATION: BERYLLIUM}

We have found that a mixture of $\mathrm{BeO}$ powder and ultrapure, finely ground silver (BeO:Ag ratio $1: 6$ to $1: 8$ by weight) gives good ion beams ( $\mathrm{BeO}^{-}$) when compressed into the central well of a Ta or an Al sputter ion source sample button. We have achieved analyzed $9 \mathrm{Be}^{+3}$ beams of up to $80 \mathrm{nA}$ and routinely work with 20 to 50nA. A sample well size of $1.52 \mathrm{~mm}$ diameter $x 0.76 \mathrm{~mm}$ depth has been as effective as a larger well size and requires only 2 to $3 \mathrm{mg}$ of BeO. Such samples reach full ion yield within an hour or so and have been run stably and effectively for as long as 12 hours.

The small sample size is especially beneficial in working with $10 \mathrm{Be}$ extracted from snow, ice, and water samples when minimum expenditure of material is desired. Techniques for quantitative recovery of $10_{\text {Be }}$ from large volumes of water

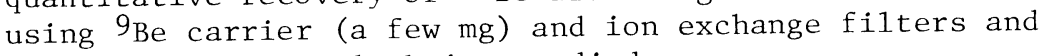
columns are currently being studied.

\section{CROSS-CONTAMINATION STUDIES}

$10^{-15}$ ), in measuring minute isotopic abundance ratios $\left(10^{-10}\right.$ to isotope (eg, $10 \mathrm{Be}$ or ${ }^{14} \mathrm{C}$ ) while optimizing the accelerator
is parameters for transmission and detection of the rare isotope. We have explored the degree to which this procedure may result in contamination of unknown samples low in the rare isotope (Farwell, Grootes, and Schmidt, 1981). The results bear also 
upon the likelihood of mutual cross-contamination among unknown samples.

Cross-contamination was observed in the following instances: 1) ${ }^{9} \mathrm{Be}$ ions were observed from $\mathrm{Ag}$ and $\mathrm{C}$ (graphite) samples exposed to operation of the sputter ion source with a natural Be metal sample. 2) Strong contamination of the same samples with $10_{\mathrm{B}}$ was also seen following brief ( $<10 \mathrm{~min}$ ) operation with a $B$ metal sample used for detector calibration. ( $10_{\mathrm{B}}$ is the principal contaminant in analyzed $10_{\mathrm{Be}}$ beams.) 3) The apparent ${ }^{10} \mathrm{Be} /{ }^{9} \mathrm{Be}$ ratios of 1 ow-1eve1 ( $10^{-12}$ or less) $\mathrm{BeO} / \mathrm{Ag}$ samples were grossly altered during operation with a Be metal sample enriched in $10_{\mathrm{Be}}$. We present here the results of this third study, which has clear implications for the measurement of low-level samples of both carbon and beryllium.

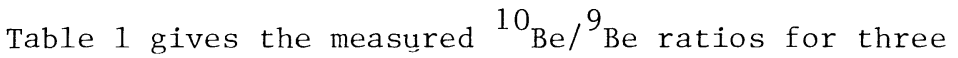
beryllium samples made in our standard fashion (BeO powder/ finely powdered $\mathrm{Ag}$ ) both before and after exposure to extended operation of the sputter source with a Be metal sample enriched in $10_{\mathrm{Be}}$. The samples were mounted on a circle $10 \mathrm{~cm}$ in diameter, in a 20-place rotating holder; their relative positions can be seen from the indicated position numbers (非20 is next to 非 in the sequence). While the $10_{\mathrm{Be}}$ enhancement factors show an apparent correlation with distance from the contaminating source, the final ${ }^{10} \mathrm{Be} /{ }^{9} \mathrm{Be}$ ratios do not, and their values all lie between $10^{-5}$ and $10^{-4}$ of that of the contaminating sample.

We conclude that even a few minutes of operation with a high-ratio (high isotopic fraction) sample can contaminate exposed low-ratio samples at the level of $10^{-5}$ to $10^{-4}$ of the higher ratio.

TABLE 1.Cross-contamination with ${ }^{10}$ Be. Beryllium samples were mounted on a $20-$ position circular holder and mutually exposed, in a cesium sputter ion source, for periods of 10 minutes or more of operation for each sample.

\begin{tabular}{|c|c|c|c|c|}
\hline Sample $\&$ position & $\begin{array}{l}\text { Ratio } 10 \\
\text { Before } \\
\text { exposure }\end{array}$ & $\begin{array}{l}\rho^{9} \mathrm{Be} \\
\text { After } \\
\text { exposure }\end{array}$ & $\begin{array}{c}10_{\mathrm{Be}} \\
\text { enhancement }\end{array}$ & $\begin{array}{c}10_{\mathrm{Be} /}{ }^{\mathrm{Be}} \text { ratio } \\
\text { relative to } \\
\text { that for Be\# } 20 \\
\text { (after exposure) }\end{array}$ \\
\hline $\begin{array}{c}\text { Be metal \#20 } \\
\left(10_{\mathrm{Be}-\text {-enriched })}\right.\end{array}$ & $5.4 \times 10^{-7}+0.1$ & (Same) & (None) & 1.00 (Reference) \\
\hline $\mathrm{BeO} / \mathrm{Ag}$ & $0.8 \times 10^{-12}+0.2$ & $20 \times 10^{-12 \pm 1}$ & 25 & $3.7 \times 10^{-5}+0.2$ \\
\hline $\mathrm{BeO} / \mathrm{Ag}$ & $4.0 \times 10^{-12}+0.8$ & $35 \times 10^{-12+2}$ & 8.8 & $6.5 \times 10^{-5}+0.4$ \\
\hline $\mathrm{BeO} / \mathrm{Ag}$ & $6.0 \times 10^{-12} \pm 0.9$ & $35 \times 10^{-12} \pm 2$ & 5.8 & $6.5 \times 10^{-5} \pm 0.4$ \\
\hline
\end{tabular}


By cleaning the sputter source components and taking other measures, we reduced our $10_{\mathrm{Be}}$ background; it now corresponds typically to a ${ }^{10} \mathrm{Be} /{ }^{9} \mathrm{Be}$ ratio of $\sim 10^{-13}$ with $\mathrm{BeO} / \mathrm{Ag}$ "blank" samples that have undergone the chemical extraction process used for preparing our natural samples. For highpurity, unprocessed $\mathrm{BeO} / \mathrm{Ag}$ samples, which give a better indication of the possible level of ion source and accelerator contamination, the $10_{\mathrm{Be}}$ background is less than $10^{-13}$. For $14 \mathrm{C}$, the background from presumably ${ }^{14} \mathrm{C}$-free graphite ranged from $1 / 200$ to $1 / 400$ of contemporary carbon until recently. Studies now indicate that the principal source of contamination is the pitch used for sample preparation. With $14 \mathrm{C}$-free pitch, our $14 \mathrm{C}$ background corresponds to 55 to 58 thousand years.

\section{ACKNOWLEDGMENTS}

It is a pleasure to acknowledge the encouragement and support of Minze Stuiver. The work was materially assisted during the past year by a grant from the MJ Murdock Charitable Trust, and was also supported in part by the US Department of Energy and the National Science Foundation.

\section{REFERENCES}

Farwe11, GW, Grootes, PM, and Schmidt, FH, 1981, Accelerator mass spectrometry: cross-contamination in a sputter ion source: Am Phys Soc Bull, v 26, p 1159.

Farwe11, GW, Grootes, PM, Leach, DD, Schmidt, FH, and Stuiver, $\mathrm{M}, 1983,10_{\mathrm{Be}}$ and ${ }^{14} \mathrm{C}$ measurements with the University of Washington FN tandem accelerator, in Stuiver, M and Kra, RS, eds, Internat $1{ }^{14} \mathrm{C}$ Conf, 11 th, Proc: Radiocarbon, v 25.

Farwe11, GW, Schmidt, FH, and Grootes, PM, 1981, Accelerator mass spectrometry at the University of Washington, in Kutschera, W, ed, Symposium on accelerator mass spectrometry, Proc: Argonne Nat1 Lab pub ANL/PHY-81-1, p 100-119.

Grootes, PM, Stuiver, M, Farwe11, GW, Schad, TP, and Schmidt, $\mathrm{FH}, 1980$, Enrichment of $14 \mathrm{C}$ and sample preparation for beta and ion counting, in Stuiver, $\mathrm{M}$ and $\mathrm{Kra}$, RS, eds, Tnternat 1 ${ }^{14} \mathrm{C}$ Conf, 10th, Proc: Radiocarbon, v 22, no. 2, p 487-499. Grootes, PM, Stuiver, M, Farwe11, GW, and Schmidt, FH, 1981, Sample preparation for accelerator mass spectrometry at the University of Washington, in Kutschera, $W$, ed, Symposium on accelerator mass spectrometry, Proc: Argonne Nat1 Lab pub ANL/PHY-81-1, p 405-415.

Schmidt, FH and Fauska, H, 1982, Auto-control of injected beams in accelerator mass spectrometry (AMS): Am Phys Soc Bul1, v 27, p 526. 